\title{
The Effects of Monosodium Glutamate on Thymic and Splenic Immune Functions and Role of Recovery (Biochemical and Histological study)
}

Zeinab A. Hassan ${ }^{1,2}$, Manar Hamed Arafa ${ }^{3}$, Wafaa Ibrahim Soliman ${ }^{3}$, Hebatallah Husseini Atteia ${ }^{4}$ and Hanan Fathy Al-Saeed ${ }^{5}$

${ }^{1}$ Department of Histology and Cell Biology, Faculty of Medicine, Zagazig University, Egypt

${ }^{2}$ Department of Anatomy, Faculty of medicine, Tibah university, Madina, Saudi Arabia

${ }^{3}$ Department of Forensic Medicine and Clinical Toxicology, Faculty of Medicine, Zagazig University, Egypt

${ }^{4}$ Department of Biochemistry, Faculty of Pharmacy, Zagazig University, Zagazig, Egypt

${ }^{5}$ Department of Physiology, Faculty of Medicine for Girls, Al-Azhar University, Cairo, Egypt

\begin{abstract}
Monosodium glutamate (MSG), a flavor enhancer, is used in modern nutrition to improve food palatability. The objectives of the current study were to investigate the effect of MSG on thymus as well as spleen structures and functions. Also, to evaluate the possibility of recovery after cessation of administration. Adult male rats were divided into three groups: control, MSG ( $3 \mathrm{~g} \mathrm{MSG} / \mathrm{kg}$ body weight daily for 8 weeks by oral gavages), and Recovery (MSG for same period and then left untreated for additional 4 weeks). The results showed that MSG treatments significantly increased serum interleukin (IL)- $1 \beta$ as well as thymic and splenic malondialdehyde and decreased serum levels of IL-10 and also reduced glutathione (GSH) levels and both catalase and superoxide dismutase activities in the thymus and spleen. Histological examination showed that MSG induced a remarkable disruption in the lobular architecture of the thymus with marked decrease of the T lymphocytes with darkly stained nuclei and dilated blood sinusoid in the cortical region. Medullary region were enlarged and repopulated with small lymphocytes and dilated blood sinusoids. The cortical-medullary differentiation was difficult to be determined. Small sized splenic lymphatic follicles with absence of germinal centers and large congested blood vessels were also noticed. The differentiation between the red and the white pulps was indistinct. Recovery groups showed preserved thymic lobular architecture with repopulation of the cortical thymocytes enclosing the paler staining medulla .Splenic lymphatic follicles of different sizes with absence of germinal centers were noticed. Marginal zone is differentiated from the red pulp. Immunohistochemical staining of MSG group demonstrated a marked decrease in CD3-positive T-lymphocytes in both thymus and spleen that significantly increased in recovery group. Taken together, the data showed that MSG consumption may have immunotoxic effects on the thymus and spleen of adult rats which is reversible but the normal structure of the spleen would need time to be regained. It is recommended that further studies aimed at corroborating these findings be carried out.
\end{abstract}

Keywords: CD3; Inflammation; Monosodium glutamate; Oxidative stress; Recovery; T-lymphocytes

\section{Introduction}

Monosodium Glutamate (MSG) is one of the world's most extensively used food additives [1]. Monosodium glutamate (MSG) - a sodium salt of glutamic acid - can produce a unique taste, known as fifth taste (umami) that improve the quality of food intake by stimulating chemosensory perception and proposed in various types of patients with cancer, radiation therapy and organ transplantation [2]. This flavor enhancer is extensively used in the food industry, and in restaurants and homes. It is present in a wide variety of processed foods including flavored chips and snacks, soups or sauces (canned, packed), prepared meals, frozen foods, marinated meats, fresh sausages, bottled soy or oriental sauces, and stuffed or seasoned chicken, manufactured meats, some hams, luncheon chicken and turkey, flavored tuna, vegetarian burgers and sausages [3]. Moreover, glutamate occurs naturally in various foods including cheeses, seafood, meat broths, poultry and vegetables [4]. Although there is no problem if MSG is present in small amounts in any one food, the problem moves to a much graver scale if small amounts are in different common foods that are consumed daily. Moreover, MSG might fall under different titles, making it very difficult to determine what foods contain this additive [5].

The Food and Drug Administration (FDA) categorized MSG as a safe substance in 1959. However, the FDA commissioned a report that an unknown percentage of the population might react to MSG and develop MSG symptom complex [6]. Experimental studies showed that prolonged consumption of MSG produced a myriad of toxic effects, referred to as Chinese restaurant syndrome [7]. This syndrome was characterized by sweating, nausea, headache, chest tightness, and/or a burning sensation in the back of the neck [8]. Furthermore, longterm intake of MSG was shown to induce hyperphagia, obesity, asthma, memory impairment, and damage to hypothalamic neurons $[7,9]$. Thus, the addition of MSG to foods can ultimately be considered a health hazard.

As a primary lymphoid organ, thymus ensures that only lymphocytes able to correctly distinguish self from non-self are let loose in the body. Thymocytes are subjected both to positive and negative selection in the thymus. The concept that the thymus in adult life atrophies and becomes unimportant has now to be finally rejected [10]. Previous studies have demonstrated that maturation of new $\mathrm{T}$ cells in the human

*Corresponding author: Zeinab A. Hassan, Department of histology and cell biology, Faculty of Medicine, Zagazig University, Zagazig, Egypt and associate professor of anatomy, Faculty of medicine Tibah University, Madinah, Saud Arabia, Tel: 00201223467226; E-mail: zeinabrehim66@gmail.com

Received September 09, 2014; Accepted September 30, 2014; Published October 02, 2014

Citation: Hassan ZA, Arafa MH, Soliman WI, Atteia HH, Al-Saeed HF (2014) The Effects of Monosodium Glutamate on Thymic and Splenic Immune Functions and Role of Recovery (Biochemical and Histological study). J Cytol Histol 5: 283. doi:10.4172/2157-7099.1000283

Copyright: (C) 2014 Hassan ZA, et al. This is an open-access article distributed under the terms of the Creative Commons Attribution License, which permits unrestricted use, distribution, and reproduction in any medium, provided the original author and source are credited. 
thymus continues throughout life. Although extremely active in the fetal and perinatal period, the thymus continues to generate new $\mathrm{T}$ cells into the adult years and even into old age, supplying the diversity needed to respond to antigenic challenge [11].

Being the largest secondary lymphoid the spleen is also greatly involved in host immune response against blood borne antigens [12]. Therefore, it is considered a vital organ to assess treatmentrelated lesions. Immunotoxicity of xenobiotics or their metabolites on lymphocytes populations is represented in the spleen. Spleen is considered one of the recommended organs to evaluate enhanced histopathology of the immune system [13,14].

The cluster of differentiation 3 (CD3) T-cell co-receptor is a protein complex and is composed of 3 polypeptide chains. CD3 is initially expressed in the cytoplasm of pro-thymocytes, the stem cells from which T-cells arise in the thymus. The pro-thymocytes differentiate into common thymocytes, and then into medullary thymocytes, and at this latter stage $\mathrm{CD} 3$ antigen begins to migrate to the cell membrane. The antigen is found bound to the membranes of all mature $\mathrm{T}$ cells, and in virtually no other cell type. This high specificity, combined with the presence of $\mathrm{CD} 3$ at all stages of $\mathrm{T}$ cell development, makes it a useful immunohistochemical marker for $\mathrm{T}$ cells in tissue sections $[15,16]$. CD3-positive molecules are expressed in all mature T-lymphocytes, and are a common surface marker for them [17].

The immune system presents major adaptive mechanisms through which the body protects itself from pathogens and other harmful agents [18]. Any disturbance in the immune system could impair its capacity to defend the body against infections, as well as lead to inflammatory diseases and even enhanced tumorigenesis. The immune system is also a potential target of toxicity following chemicals exposure [19]. Oxidative stress contributes to various disorders in the body, including a comprise of the immune system. This stress occurs due to an imbalance between biological oxidants and anti-oxidants, and often gives rise to cell and organ damage $[20,21]$. Previous studies indicated that chemicals that induce oxidative stress depress immune organ/cell function [18,22].

Several studies have demonstrated that MSG causes arcuate nucleus damage [23] and is also associated with a number of pathological conditions such as epilepsy, schizophrenia, anxiety, depression, and degenerative disorders such as Parkinson's disease and Alzheimer's disease, [24,25]. It has been proved that MSG induces oxidative stress in different organs, including the pancreas [26], liver [27], kidney [28], and thymus [29-31]. Previous studies has also suggested that glutamateinduced toxicity could be mediated via necrosis and apoptosis [32]. Further, it has been shown that MSG increased apoptosis of thymocytes in rats, in part, by down-regulation of anti-apototic (Bcl-2) gene expression [33]. Recent studies have shown that glutamate not only has a role as neurotransmitter, but also as an important immunomodulator [34]. Based on those earlier observations, the objective of this study was to explore immunomodulatory changes induced by MSG in the thymus and spleen and the possibility of their reversal.

\section{Materials and Methods}

\section{Animals}

The current study was performed using 30 albino rats (male, 150-180 g, 12-16-weeks-old) obtained from the Faculty of Veterinary Medicine, Zagazig University. Rats were housed in stainless steel cages and maintained under standardized environmental conditions $\left(25^{\circ} \mathrm{C}\right)$ away from any stress with a 12-hr light/dark cycle and 50\% humidity. All rats had ad libitum access to standard rodent chow and filtered water. Rats were acclimatized for 1 weeks before use in the experiments. The Ethics Committee for Animal Handling at Zagazig University (ECAHZU), based on National Institutes of Health (USA) guidelines, approved all protocols used herein.

\section{Reagents}

Monosodium glutamate (MSG) $\left(\mathrm{C}_{5} \mathrm{H}_{9} \mathrm{NO}_{4} \cdot \mathrm{Na}\right.$; purity $\left.>98 \%\right)$ was obtained from Al-Dawlya Chemicals Co. (Cairo, Egypt). All other chemical reagents used here for the various analyses were from Sigma (St Louis, MO), unless elsewise indicated.

\section{Preparation of MSG and treatment regimens}

For use in the experiments, the MSG was dissolved in distilled water. For the exposures, rats were randomly allocated into three groups (N=10/group): Group I (control group) rats received $1 \mathrm{ml}$ distilled water daily (MSG vehicle) for 8 weeks by oral gavages; Group II (MSG group) rats received $3 \mathrm{~g} / \mathrm{kg}$ body weight of MSG $\left(1 / 5 \mathrm{LD}_{50}\right)$ daily for 8 weeks by oral gavages $[35,36]$ and Group III (recovery group) rats received the same dose of MSG for the same period as Group II rats and then nothing for a subsequent 4 weeks after the final MSG dosing. Rats were weighed daily to allow for adjustment of the daily dose volume; in no case did the volume of MSG used for treatment ever exceed $3 \mathrm{~g} / \mathrm{kg}$.

\section{Rational for selection of dose, duration of the study and recovery period}

Glutamate receptors are present on every major organ. Humans are 20 times more sensitive than monkeys, 5 times more sensitive than rats to MSG. [5]. The lowest dose in the previously mentioned studies was $2 \mathrm{~g} / \mathrm{kg}$ of body weight that corresponds to an ingestion of $140 \mathrm{~g}$ in a $70 \mathrm{~kg}$ man. Furthermore, animal studies results are applicable with difficulty to humans as human food is much more diverse, rich and combined with another substances potentially leading to potentiation or inhibition of particular compounds effects. The median lethal dose $\left(\mathrm{LD}_{50}\right)$ is between 15 and $18 \mathrm{~g} / \mathrm{kg}$ body weight in rats and mice [37]. The selected dose was based on the toxicity levels reported by previous studies $[35,36]$. The duration of the study ( 8 weeks) may provide the potential for long-term effects associated with MSG intake. A number of studies have indicated that the effects of MSG can occur cumulatively over time with subsequent exposure [38]. Initially, there was no visible damage, but multiple exposures over a period of time led to the irreparable injury.

Rats were left untreated for 4 weeks post treatment to allow them to recover and to observe for reversibility, persistence or delayed occurrence of any effect according to Kingsley et al., [39].

\section{Blood and Tissue Sampling}

Twenty-four hr after the final dosing/non-dosing day, the rats (who had been fasted over-night) were weighed and injected intraperitoneally with $50 \mathrm{mg}$ pentobarbital/kg body weight. Blood samples were then collected from the retro-orbital plexus and serum was subsequently isolated and then stored at $-80^{\circ} \mathrm{C}$ for later use in determinations of levels of interleukin (IL)- $1 \beta$ and IL-10. The rats were then euthanized by decapitation and their thymus and spleen were harvested. Each organ was divided into two parts; one was flash frozen in liquid $\mathrm{N}_{2}$ and stored at $-80^{\circ} \mathrm{C}$ for later use in measures of malondialdehyde (MDA) and reduced glutathione (GSH) contents as well as catalase (CAT) and superoxide dismutase (SOD) activities. The other part was processed for histological examination. 


\section{Biochemical Analysis}

Serum IL-1 $\beta$ and IL-10 levels were assayed using Quantikine ELISA kits (R\&D Systems Inc., Minneapolis, MN). Sensitivity of the kits was 5 pg IL- $1 \beta / \mathrm{ml}$ and $10 \mathrm{pg}$ IL-10/ml. Thymic and splenic contents of MDA (indices of lipid peroxidation) were determined spectrophotometrically using a commercial kit (Dokki Biodiagnostic, Giza, Egypt). Briefly, an aliquot of tissue extract supernatant was mixed with $1 \mathrm{ml}$ $5 \%$ trichloroacetic acid and then centrifuged at $2500 \times \mathrm{g}$ for $10 \mathrm{~min}$. Supernatant $(0.2 \mathrm{ml})$ was transferred to a test tube, and then $0.2 \mathrm{ml}$ of $8.1 \%$ sodium dodecyl sulfate (SDS), $1.5 \mathrm{ml}$ of $30 \%$ acetic acid $(\mathrm{pH}=$ 3.5 ), and $1.5 \mathrm{ml}$ of $0.8 \%$ thiobarbituric acid (TBA) were added. The tube was mixed, covered with glass beads, heated in waterbath $\left(\right.$ at $\left.95^{\circ} \mathrm{C}\right)$ for $30 \mathrm{~min}$, and then cooled. After centrifugation $(4000 \times \mathrm{g}, 10 \mathrm{~min})$, the supernatant was isolated and absorbance of the pink color was measured at $532 \mathrm{~nm}$ in Model UVD-2950 scanning spectrophotometer (Labomed Inc., Los Angeles, CA). A standard curve was generated using 1,1,3,3-tetraethoxypropane; from this curve, MDA levels in each sample were extrapolated. All data were expressed as nmol MDA/g tissue processed.

Reduced glutathione (GSH) contents in the thymus and spleen were assessed according to the method of Ahmed et al. [40] based on a 5,5'-dithiobis-2-nitrobenzoic acid (DTNB) reaction. Briefly, $0.1 \mathrm{~g}$ tissue was homogenized in $1 \mathrm{ml}$ phosphate buffer $(\mathrm{pH}=8)$ at $4^{\circ} \mathrm{C}$. An aliquot ( $0.5 \mathrm{ml}$ of homogenate) was mixed with $0.5 \mathrm{ml} 10 \%$ TCA in $5 \mathrm{mM}$ EDTA solution and the mixture was then centrifuged at $2000 \mathrm{x}$ g for 5 min. The supernatant generated was used for the determination of GSH at $412 \mathrm{~nm}$ in the spectrophotometer [41]. As total protein content was needed for calculation of GSH content in the tissues, this parameter was determined using a Biocon Diagnostik kit (GmbH, Vohl-Marienhagen, Germany). All data were expressed as nmol GSH/mg protein.

Tissue CAT activity was assessed colorimetrically using the method of Aebi (1984) [42] which is based on the fact that if CAT reacts with a known quantity of $\mathrm{H}_{2} \mathrm{O}_{2}$ and the reaction is then stopped after $1 \mathrm{~min}$ (using CAT inhibitor), in the presence of a peroxidase (horseradish peroxidase [HRP]), any remaining $\mathrm{H}_{2} \mathrm{O}_{2}$ reacts with 3,5-dichloro2-hydroxybenzene sulfonic acid (DCHBS) and 4-aminophenazone (AAP) to form a chromophore. Ultimately, the color intensity is inversely proportional to the amount of CAT that is present in the original sample. For this assay, $50 \mathrm{ml}$ tissue homogenate supernatant was placed in a cuvette containing $500 \mu 1100 \mathrm{mM}$ phosphate buffer $(\mathrm{pH}$ 7.0) and $1 \mathrm{mM}$ DCHBS. To this, $1 \mathrm{ml}$ of $0.05 \mathrm{mM} \mathrm{H}_{2} \mathrm{O}_{2}$ was added and the mixture was incubated $1 \mathrm{~min}$ at $25^{\circ} \mathrm{C}$. After $1 \mathrm{~min}, 100 \mu \mathrm{l}$ of CAT inhibitor ( $15 \mathrm{mM}$ sodium azide) and $500 \mu \mathrm{l}$ of a solution containing HRP $(2 \mathrm{U} / \mathrm{ml})$ and $2 \mathrm{mM} \mathrm{4}$-aminoantipyrine were added and the mixture was incubated a further $10 \mathrm{~min}$ at $37^{\circ} \mathrm{C}$. The level of resulting quinoneimine dye was then measured spectrophotometrically at 510 $\mathrm{nm}$. Total activity was expressed as $\mathrm{U} / \mathrm{g}$ tissue where $1 \mathrm{U}=$ the amount of catalase that decomposes $1 \mu \mathrm{mol} \mathrm{H}_{2} \mathrm{O}_{2} /$ per min [43].

Tissue SOD activity was measured according to the method of Nishikimi et al. [44]. An aliquot of splenic or thymic homogenate supernatant $(50 \mu \mathrm{l})$ was combined to $100 \mu \mathrm{l}$ sodium pyrophosphate buffer ( $\mathrm{pH} 8.3$ ), $0.1 \mathrm{ml}$ of $0.3 \mathrm{M}$ nitroblue tetrazolium, and $0.1 \mathrm{ml}$ of $780 \mu \mathrm{M}$ NADH; after mixing, $10 \mu \mathrm{l}$ of $186 \mu \mathrm{M}$ phenazine methosulfate (PMS) solution was added to initiate the reaction. Because SOD enzyme inhibits PMS-mediated reduction of nitroblue tetrazolium, the rate of increase in absorbance (measured at $560 \mathrm{~nm}$ ) was used to reflect SOD content in the sample. All data were ultimately reported as U/g tissue, with $1 \mathrm{U}=$ the amount of enzyme required to produce a $50 \%$ inhibition in NBT reduction [45].

\section{Histology}

The dedicated portion of isolated thymus and spleen from each rat was placed in $10 \%$ buffered formalin. After $10 \mathrm{~min}, 1-\mathrm{cm}^{3}$ specimens were fixed in $10 \%$ buffered formalin for $24 \mathrm{hr}$ and then processed to yield $5-\mu \mathrm{m}$ sections. Some of these sections were stained with haematoxy-lin and eosin (H\&E) to verify histological details via light microscopy [46]. Other sections were de-paraffinized, placed on charged slides, and used for localization of CD3 on cells. Anti-CD3 antibodies were employed to stain the cells in an avidin-biotin-complex (ABC) immunoperoxidase technique. Specifically, the sections were incubated in $5 \% \mathrm{H}_{2} \mathrm{O}_{2}$ (in methanol) solution for 10 min to block endogenous peroxidase activity and then incubated with primary anti-CD3 rabbit monoclonal antibody (1:50 dilution in $1 \%$ bovine serum albumin solution; Pan-T Clone SP7, Thermo Scientific, LabVision, Fremont, CA) for $60 \mathrm{~min}$ at room temperature. After rinsing with phosphate-buffered saline (PBS, $\mathrm{pH}$ 7.4) to remove unbound primary antibody, the samples were incubated with diaminobenzidine (DAB) chromogen solution for $5 \mathrm{~min}$ at $25^{\circ} \mathrm{C}$. The sections were then counterstained with haematoxylin for $15 \mathrm{sec}$. Normal tissues were used as positive control; a negative control was generated using the same tissue (normal tissues) but omitting the primary antibody [47].

\section{Morphometric study}

Quantitative morphometric measurements were obtained using a Leica Qwin 500 image analyzer computer system (Leica, Hessen, Germany): Faculty of Medicine, Zagazig University, Egypt. Immunoreactive optical density for CD-3were estimated. The optical density was determined randomly in the thymus cortex and PALS of spleen. Measurements were taken in 10 randomly selected nonoverlapping fields from each animal. All Morphometric measurements were taken at total magnification $\mathrm{X} 400$. $\mathrm{p}$-value $<0.05$ was considered statistically significant.

\section{Statistical Analysis}

All results were expressed as mean \pm SD. Differences among the groups were analyzed via a one-way analysis of variance (ANOVA) followed by a Tukey-Kramer post-hoc test for inter-group comparisons using SPSS software (v.16; SPSS Inc., Chicago, IL).

\section{Results}

\section{Body weight}

Monosodium glutamate (MSG) administration induced a significant increase in rat body weight $(\mathrm{p}<0.0001)$ when compared with control rat values. Stopping administration of the MSG significantly reduced these values toward normal $(\mathrm{p}<0.01)$ (Table 1$)$.

\section{Serum IL-1ßand IL-10 levels}

In MSG-treated rats, serum IL-1 $\beta$ level was increased 1.6-fold with respect to control group levels. This increase was attenuated after withdrawal of MSG ( $\mathrm{p}<0.0001)$. Administration of MSG also caused a significant decrease in serum IL-10 $(\mathrm{p}<0.001)$. Again, the recovery ameliorated the MSG-induced reduction $(\mathrm{p}<0.0001)$ (Figure 1).

\begin{tabular}{|c|c|c}
\hline Control group & MSG-only group & Recovery group \\
\hline $160.0 \pm 15.4$ & ${ }^{a} 213.0 \pm 20.8$ & ${ }^{b} 184.0 \pm 17.8$
\end{tabular}

Results are expressed as mean $\pm \mathrm{SD}(\mathrm{N}=10$ rats/group).

aValue significantly different from control group $(p<0.0001)$ and bMSG group ( $p$ $<0.01$ ).

Table 1: Effect of monosodium glutamate (MSG) on body weights of rats. 


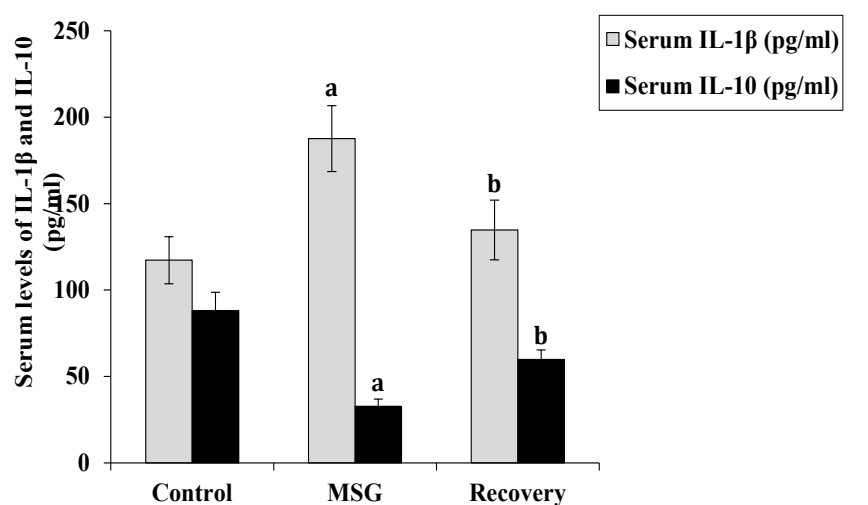

Figure 1: Serum interleukin (IL)-1 $\beta$ and IL-10 levels. Values obtained from rats treated daily with MSG ( $3 \mathrm{~g} / \mathrm{kg}$ body weight) for 8 weeks; with some rats, there was a 4-weeks recovery period. Data are expressed as mean \pm SD of 10 rats/group. aValue significantly different from control group at $p<0.0001$ and bsignificantly different from MSG group at $p<0.0001$

\begin{tabular}{|l|c|c|c|}
\hline Parameter & Control group & MSG group & Recovery group \\
\hline Thymic MDA (nmol/g tissue) & $69.68 \pm 7.31$ & $\mathrm{a} 141.30 \pm 5.47$ & ${ }^{\mathrm{b}} 98.81 \pm 9.19$ \\
\hline Splenic MDA (nmol/g tissue) & $80.58 \pm 4.28$ & $\mathrm{a} 165.32 \pm 12.49$ & ${ }^{\mathrm{b}} 99.70 \pm 15.3$ \\
\hline Thymic GSH (nmol/mg protein) & $13.61 \pm 0.66$ & ${ }^{\mathrm{a}} 4.13 \pm 0.19$ & ${ }^{\mathrm{b}} 9.41 \pm 1.08$ \\
\hline Splenic GSH (nmol/mg protein) & $28.21 \pm 1.47$ & ${ }^{\mathrm{a}} 9.07 \pm 0.47$ & ${ }^{\mathrm{b}} 17.42 \pm 0.87$ \\
\hline Thymic CAT (U/g tissue) & $60.47 \pm 2.22$ & ${ }^{\mathrm{a}} 41.36 \pm 4.44$ & ${ }^{\mathrm{b}} 47.20 \pm 4.63$ \\
\hline Splenic CAT (U/g tissue) & $85.13 \pm 3.96$ & ${ }^{\mathrm{a}} 61.69 \pm 3.80$ & ${ }^{\mathrm{b}} 78.38 \pm 3.94$ \\
\hline Thymic SOD (U/g tissue) & $17.13 \pm 0.81$ & ${ }^{\mathrm{a}} 6.31 \pm 0.54$ & ${ }^{\mathrm{b}} 12.09 \pm 0.58$ \\
\hline Splenic SOD (U/g tissue) & $36.28 \pm 1.73$ & ${ }^{\mathrm{a}} 14.48 \pm 2.32$ & ${ }^{\mathrm{b}} 24.18 \pm 1.13$ \\
\hline
\end{tabular}

Results are expressed as mean $\pm \mathrm{SD}$ ( $\mathrm{N}=10$ rats/group).

avalue significantly different from control group $(p<0.001)$ and ${ }^{\mathrm{b}} \mathrm{MSG}$ group $(p<$ 0.05).

MDA: malondialdehyde; GSH: reduced glutathione; CAT: catalase; SOD: superoxide dismutase.

Table 2: Effect of MSG administration on malondialdehyde (MDA) level, reduced glutathione (GSH) content, and anti-oxidant enzymes activities in rat thymic and splenic tissues.

Serum IL-10:IL-1 $\beta$ ratios were significantly decreased from 0.76 in the control rats to 0.18 in the MSG rats $(\mathrm{p}<0.0001)$. Cessation of MSG administration increased this ratio to $0.45(\mathrm{p}<0.0001)$, reflecting a somewhat restoration of the balance between pro-inflammatory and anti-inflammatory cytokines.

\section{Oxidative stress and anti-oxidant parameters in the thymus and spleen}

Rats treated with MSG exhibited a significant increase in MDA content in both thymic and splenic tissues $(\mathrm{p}<0.001)$ compared to control values. Cessation of MSG administration for 4 weeks significantly reduced these tissues MDA contents $(p<0.05)$. MSG administration also resulted in a significant reduction in GSH contents in both thymic and splenic tissues $(\mathrm{p}<0.001)$ compared to control values that was also reversed by the recovery period. Activities of SOD and CAT (anti-oxidant enzymes) were decreased in MSG-treated animals in comparison with levels in their control counterparts, but increased in the recovery group $(\mathrm{p}<0.05)$ (Table 2$)$.

\section{Correlations between measured biochemical parameters}

Analysis of the combined results from all tested rats revealed that serum IL- $1 \beta$ levels were positively correlated with body weight $(r=0.95$, $\mathrm{p}<0.0001)$, thymic $(\mathrm{r}=0.9, \mathrm{p}<0.0001)$ and splenic MDA contents $(\mathrm{r}=0.92, \mathrm{p}<0.0001)$. In contrast, it was negatively correlated with thymic GSH content $(\mathrm{r}=-0.78, \mathrm{p}<0.0001)$, SOD $(\mathrm{r}=-0.79, \mathrm{p}<0.0001)$ and CAT $(\mathrm{r}=-0.69, \mathrm{p}<0.0001)$ activities as well as splenic GSH content $(\mathrm{r}=-0.78, \mathrm{p}<0.0001)$, SOD $(\mathrm{r}=-0.74, \mathrm{p}<0.0001)$, and CAT activities $(\mathrm{r}=-$ $0.84, \mathrm{p}<0.0001)$. On the other hand, there was a positive correlation among serum IL-10, thymic GSH content, SOD $(\mathrm{r}=0.98, \mathrm{p}<0.0001)$ and CAT activities $(\mathrm{r}=0.88, \mathrm{p}<0.0001)$ as well as splenic GSH content $(\mathrm{r}=0.98, \mathrm{p}<0.0001)$, SOD $(\mathrm{r}=0.99, \mathrm{p}<0.0001)$ and CAT activities $(\mathrm{r}=0.86, \mathrm{p}<0.0001)$. A negative correlation was observed among serum IL-10, thymic $(r=-0.89, \mathrm{p}<0.0001)$ and splenic MDA contents $(\mathrm{r}=-0.84$, $\mathrm{p}<0.0001)$.

\section{Histological findings}

The examination of H\&E-stained sections of control rat thymuses revealed many lobules partially separated by thin bands of connective tissue. Distinct cortex containing many densely packed cells of thymocytes, epithelial cells and deeply stained bodies was observed. Tingible body macrophages (macrophages containing stainable bodies or cellular debris) were detected. Paler staining medullas with Hassell's corpuscles were also seen (Plates 1A and 1B). Examination of thymus sections from the MSG-treated rats showed different degrees of lobular affection. Some lobules were separated by relatively thick bands and congested blood vessels. Dark-staining cortex with increased numbers of lymphocytes with darkly stained nuclei and tingible macrophages were also noticed. The medulla showed many empty spaces and vacuolated epithelial cells and Hassell's corpuscles (Plates 1C and 1D). The affected lobules revealed loss of normal lobular architecture; the capsules were expanded by edematous fluid, with a few interspersed inflammatory cells. Decreases in the number of T-lymphocytes with different sizes and darkly-stained nuclei and dilated blood sinusoid were also seen in the cortical region. The medullary region was enlarged and re-populated with small lymphocytes and dilated blood sinusoids. Cortical-medullary differentiation was difficult to determine due to lack of normal cortical tissues (Plates $1 \mathrm{E}$ and $1 \mathrm{~F}$ ). Examination of the recovery rat samples indicated there was a relatively thick connective tissue septum. Thymic tissues with re-population by cortical thymocytes were seen enclosing the paler staining medulla. T-lymphocytes with darkly stained nuclei were also seen (Plates $1 \mathrm{G}$ and $1 \mathrm{H}$ ). Immunoperoxidase staining for $\mathrm{CD} 3$ in the control group thymus samples revealed numerous strong immunoreactive T-lymphocytes, mainly in the cortex (Plates 2A and 2B). In the tissues from the MSG rats, there were weak immunoreactions by cells in the cortex and moderate reactivity in the medulla (Plates $2 \mathrm{C}$ and 2D). Examination of tissues from the recovery group rats indicated that there were many positive T-lymphocytes, mainly in cortical regions (greater than those in the medullary region) (Plates $2 \mathrm{E}$ and $2 \mathrm{~F}$ ).

H\&E-stained sections of control group spleens displayed white pulps formed of eccentric arteriole surrounded by periarterial lymphatic sheath (PALS) and well-circumscribed lymphoid follicles. Germinal centers appeared as lightly-stained areas in the center of secondary lymphoid follicles. Marginal zones with many aggregations of darkly-stained lymphocytes were clearly differentiated from the red pulp. Many blood cells were also noted in the pulp (Plates $3 \mathrm{~A}$ and 3B). On examining sections of spleens from MSG-treated rats, smallsized lymphatic follicles with an absence of germinal centers and large congested blood vessels with thick walls were seen. The differentiation between red and white pulps was indistinct. Many lymphocytes with different sizes and darkly stained nuclei, blood cells and splenic sinusoids were scattered in red pulps (Plates 3C and 3D). Examination 
Citation: Hassan ZA, Arafa MH, Soliman WI, Atteia HH, Al-Saeed HF (2014) The Effects of Monosodium Glutamate on Thymic and Splenic Immune Functions and Role of Recovery (Biochemical and Histological study). J Cytol Histol 5: 283. doi:10.4172/2157-7099.1000283
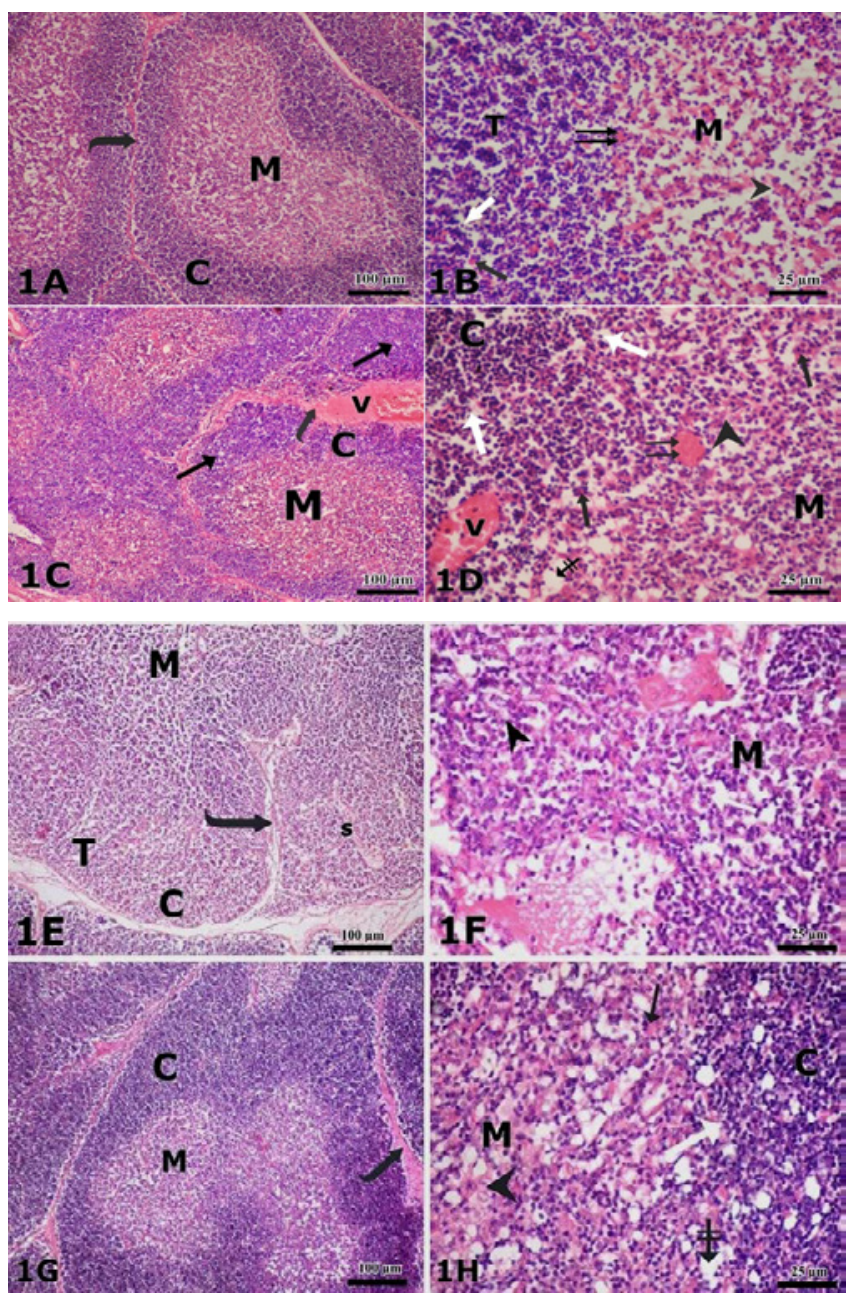

Plate 1: Representative Micrographs of Thymus. (A,B) Control rat tissue showing that thymus is partially subdivided into lobules separated by thin bands of connective tissue (curved arrow). Cortex (C) contains numerous densely packed cells of thymocytes ( $T$ ), epithelial cells (arrowhead), and deeply stained bodies (white arrows) and tingible body macrophages (arrow) enclosing paler staining medulla (M) with Hassell's corpuscle (double arrows) (C, D) MSG-treated rat tissue evidencing thymic lobules separated by relatively thick bands (curved arrow) contain congested vessel (v). Dark-staining cortex shows increased numbers of lymphoytes with darkly stained nuclei (white arrows) and tingible body macrophages (arrow). The medulla shows many empty spaces (crossed arrow), Hassell's corpuscles (double arrows) and vacuolated epithelial cells (arrowhead). H\&E stain. (Images scale bar, A,C, $100 \mu \mathrm{m} \& \mathrm{~B}, \mathrm{D} ; 25 \mu \mathrm{m})$

$(\mathrm{E}, \mathrm{F})$ : Dramatically-affected lobules show expanded connective tissue septa (curved arrow) by edematous fluid with a few interspersed inflammatory cells. Marked decrease in cortical thymocytes with different sizes and darkly-stained nuclei and dilated blood sinusoids (s) are seen. Medullary region is enlarged and re-populated with small lymphocytes (arrow) and dilated blood sinusoids (s). Cortical-medullary differentiation is difficult to determine. (G, H) Recovery group rat tissues with re-population of cortical thymocytes enclosing paler staining medulla are seen. Relatively thick connective tissue septa (curved arrow) and T-lymphocytes with darkly stained nuclei are also seen (white arrow). H\&E stain. (Images scale bar, E,G; $100 \mu \mathrm{m} \& \mathrm{~F}, \mathrm{H} ; 25 \mu \mathrm{m}$ )

of recovery group showed lymphatic follicles of different sizes with absence of germinal centers. Aggregates of darkly stained lymphocytes were observed within follicles. Marginal zone was differentiated from the red pulp. Also, many blood cells were noticed within blood sinusoids (Plates $3 \mathrm{E}$ and $3 \mathrm{~F}$ ). Spleen sections from the control rats revealed large numbers of $\mathrm{CD}^{+} \mathrm{T}$-lymphocytes, mainly around the central artery forming PALS in the white pulp (Plates $4 \mathrm{~A}$ and $4 \mathrm{~B}$ ). In contrast, a decrease in $\mathrm{CD}^{+}$T-lymphocyte numbers was noted in the PALS of spleens from MSG-treated rats. In addition, the majority of cells were weakly stained, and only a few had a strongly positive reaction (Plates $4 \mathrm{C}$ and $4 \mathrm{D}$ ). Sections of spleen from recovery rats revealed restoration of the number of $\mathrm{CD}^{+}$T-lymphocytes, mainly around the central artery forming the PALS (Plates $4 \mathrm{E}$ and $4 \mathrm{~F}$ ).

\section{Histological morphometrical and Statistical Results}

The mean optical density of CD-3 expression for all groups is presented in Table 1. There was a significant decrease $(\mathrm{P}<0.05)$ in CD-3 expression in MSG-treated group (II) compared with control group (I). There was a significant increase $(\mathrm{P}<0.05)$ in $\mathrm{CD}-3$ expression in recovery group (III) compared with MSG-treated group (II) (Table 3).

\begin{tabular}{|l|c|c|c|}
\hline & Group I & Group II & Group III \\
\hline Thymus & $1.357 \pm 0.066005$ & $1.0880 .064773 \mathrm{a}$ & $1.233 \pm 0.069769^{\mathrm{b}}$ \\
\hline Spleen & $1.572 \pm 0.042374$ & $1.148 \pm 0.066466 \mathrm{a}$ & $1.35 \pm 0.068638^{\mathrm{b}}$ \\
\hline
\end{tabular}

a significant difference with the group I

b significant difference with the group II

Results are expressed as mean $\pm \mathrm{SD}(\mathrm{N}=10$ rats/group) p value $(<0.05)$.

Table 3: Showing the mean optical density of CD-3 positive immune-expression in all studied groups.

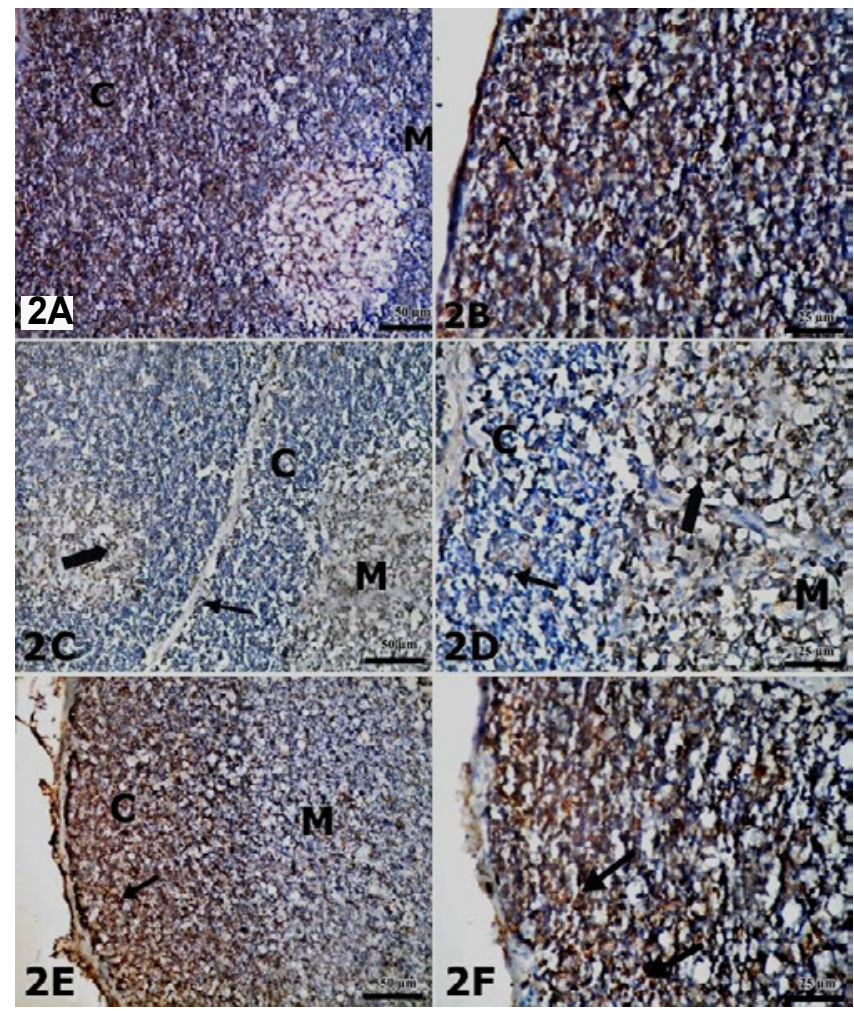

Plate 2: Representative Micrographs of Thymus Using Immunoperoxidase Staining for CD3. (A, B) Control rat tissue showing numerous strong positive brown immuno-reactions for T-lymphocytes (arrow) mainly in cortex (C) enclosing medulla (M) with weak immunoreaction. (C, D) MSG-treated rat tissue with weak positive immunoreactions for T-lymphocytes (arrow) in cortex and moderate immunoreactions (thick arrow) is noticed in medulla. (E, F) Recovery group rat tissue showing T-lymphocytes (arrow), mainly in cortex (more so than in medulla). (Images scale bar, C,E; $100 \mu \mathrm{m} \& \mathrm{D}, \mathrm{F} ; 25 \mu \mathrm{m}$ ) 
Citation: Hassan ZA, Arafa MH, Soliman WI, Atteia HH, Al-Saeed HF (2014) The Effects of Monosodium Glutamate on Thymic and Splenic Immune Functions and Role of Recovery (Biochemical and Histological study). J Cytol Histol 5: 283. doi:10.4172/2157-7099.1000283

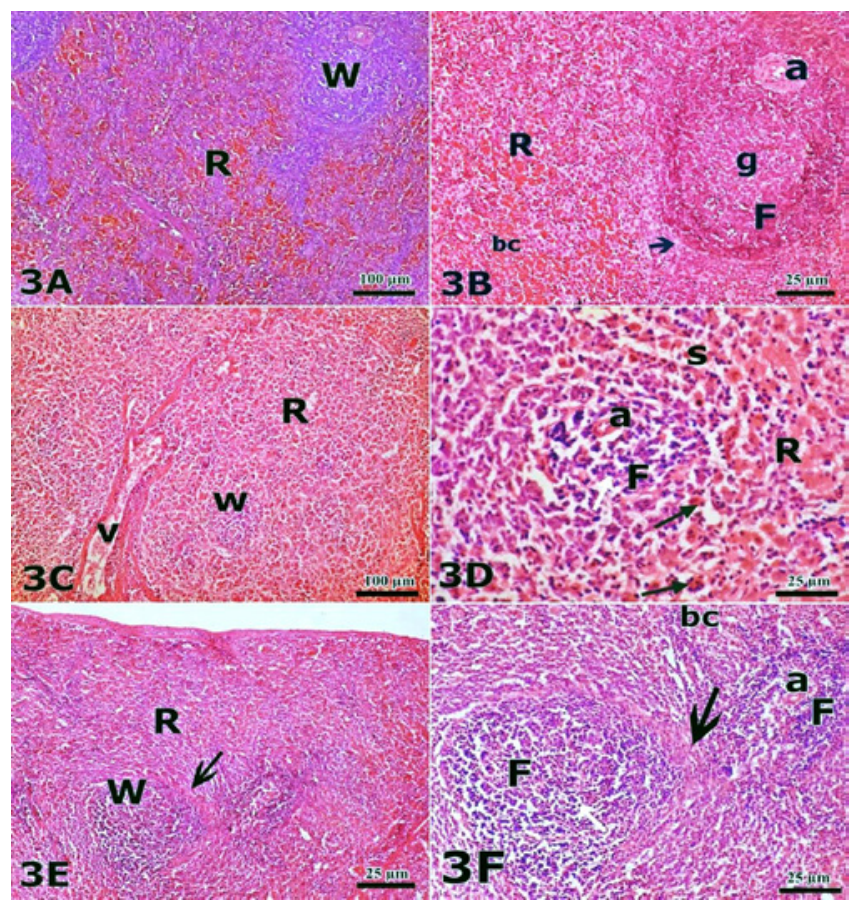

Plate 3: Representative Micrographs of Spleen. (A, B) Control rat tissue with normal red $(R)$ and white $(W)$ pulp. Secondary lymphatic follicle $(F)$ with pale staining germinal center $(\mathrm{g})$ and small central artery $(\mathrm{a})$ are also seen. A marginal zone (arrow) is clearly differentiated from the red pulp. Many blood cells $(\mathrm{bc})$ are also noticed in the red pulp $(\mathrm{C}, \mathrm{D})$ MSG-treated rat tissue showing small sized lymphatic follicles with no germinal centers and large congested blood vessel (v). Differentiation between red and white pulp is indistinct. Many lymphocytes (arrow) with different sizes and darkly stained nuclei are seen in the white pulp and blood cells. Splenic sinusoids (s) are scattered in the red pulp. (E, F) Recovery group rat tissue shows lymphatic follicles of different sizes with absence of germinal centers. Many aggregations of darkly stained lymphocytes (white arrow) and eccentric artery (a) are seen within the follicles. A marginal zone (arrow) is differentiated from the red pulp. Many blood cells are present within dilated blood sinusoids. H\&E stain. (Images scale bar, A,C,E; $100 \mu \mathrm{m} \&$ B, D, F; $25 \mu \mathrm{m})$.

\section{Discussion}

Monosodium glutamate (MSG) is frequently used as a flavor enhancer and one of the most applied food additives used in modern nutrition worldwide [48]. Thymus is responsible for generation of most of circulating T-cells and specifically, play an important role in maintaining the immune reaction of the spleen [12] Thus, alteration of T-lymphocytes in response to MSG consumption could reflect MSGinduced immunotoxicity.

The current study showed that MSG administration, lipid peroxidation and a depletion of anti-oxidants in the thymus and spleen, a precursor to the pathogenesis of many diseases. Similar findings were reported in an earlier study; MSG significantly increased malondialdehyde (MDA) levels and decreased catalase (CAT) activity in thymic tissues [31]. They suggested that MSG induced oxidative stress in the thymus and spleen, increasing their sensitivity to lipid peroxidation. On the other hand, stopping the MSG administration resulted in a significant reduction in lipid peroxidation and repletion of anti-oxidants in the thymus and spleen. These findings support those of a previous study reporting that over-expression of CAT protected thymocytes against oxidative injury and apoptosis [49].

Cytokines are cell-signaling proteins secreted to mediate the immune response of a body and to regulate inflammatory processes [50]. The family of cytokines includes pro-inflammatory proteins, such as tumor necrosis factor (TNF)- $\beta$, IL- $1 \beta$, and IL-6, and antiinflammatory ones like IL-10. Pro-inflammatory cytokines allow organisms to respond to infectious agents and induce inflammation; over-production of these agents can occur as well, leading to chronic inflammation and/or autoimmunity [51,52]. While the immune system and its cells have mechanisms to inhibit the inflammation induced by these cytokines [53], changes in levels of these proteins can serve as an indirect index to assess immune function status [54].

Administration of MSG to mice increased their mRNA expression of inflammatory genes including those for IL-6 and TNF $\beta$ [55-57], This was believed to be attributed to an increase in fat tissue and dual activation of peroxisome proliferator-activated receptors (PPAR) $\alpha$ and $\Upsilon$ [57]. Several studies have demonstrated that obesity is associated with a chronic low-grade inflammation [58]. It is also known that visceral adipose tissues synthesize and secrete cytokine and adipokines like IL$1 \beta$, IL-6, TNF, resistin, adiponectin and leptin $[59,60]$. The study here showed also that MSG increased IL-1 $\beta$ and decreased IL-10 levels in serum, reflecting a reduction in the ratio between circulating anti- and pro-inflammatory cytokines. The increase in IL- $1 \beta$ might be attributed to obesity since it was coupled with an increase in the body weights of the rats. In addition, the oxidative stress itself might be causative for the increase in release of IL- $1 \beta$ after the MSG dosing. In contrast, stopping MSG administration led to a normalizing of body weight and serum IL- $1 \beta$ and an elevation of serum IL-10 levels, thereby restoring a balance between pro- and anti-inflammatory cytokines in the blood.

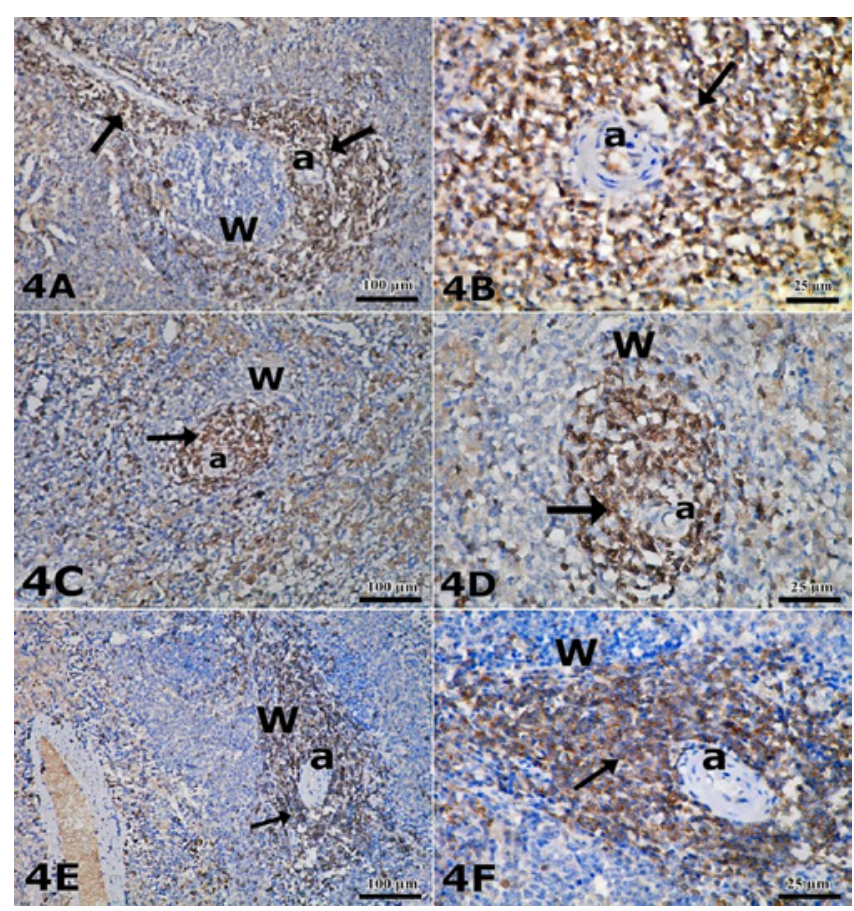

Plate 4: Representative Micrographs of Spleen Using Immunoperoxidase Staining for CD3. (A, B) Control rat tissue showing numerous strong brown positive immunoreactions for T-lymphocytes (arrow) noticed mainly around the central artery (a) forming periarterial lymphatic sheath (PALS) in white pulp (W). (C, D) MSG-treated rat tissue showing depletion of T-lymphocytes (arrow) in PALS around central artery (a) of white pulp. (E, F) Recovery group rat tissue showing many positive T-lymphocytes (arrow) in PALS in white pulp. (Images scale bar, A,C,E; $100 \mu \mathrm{m} \& \mathrm{~B}, \mathrm{D}, \mathrm{F} ; 25 \mu \mathrm{m})$. 
In contrast, IL-10 is an anti-inflammatory cytokine produced in large amounts from activated B-lymphocytes that mature in the marginal zone of the spleen. It has been suggested that IL-10-producing B-cells play a regulatory role in suppressing harmful immune responses $[61,62]$. IL-10 has been shown to slow down progression of apoptosis in immuno-derived cells. IL-10 prevents the increase in nuclear factor kappa-light-chain-enhancer of activated B cells (NF-kB) binding activity evoked by glutamate [63]. This effect was shown previously to be causally involved in glutamate-mediated cell death [64]. Thus, our findings that MSG intake reduced serum IL-10 levels might imply that this agent is also inducing splenic hypo-function and atrophy. Once again, oxidative stress might also be involved in this process. In support of this notion, it was found that $\mathrm{N}$-acetyl cysteine (antioxidant) attenuated lipopolysaccharide induced apoptosis in splenic lymphocytes [65]. The data presented here indicated that in fact there was a strong positive correlation among the changes in serum IL10 levels and the loss of thymic and splenic anti-oxidants; this lends credence to the potential role that oxidative stress might be having in mediating the immunotoxicity of MSG.

While mechanisms contributing to chemically-induced immunotoxicity are not clearly understood [66], oxidative damage is a possible mechanism [67] Several studies have shown that exposure to pesticides induced oxidative stress, depression of immune function, and pathological changes in splenic lymphocytes [21,54,68-71]. The upregulation of IL- $1 \beta$ and TNF in the spleen following pesticide-exposure reflected inflammation and a decline in host immune function [54]. In line with the potential role of MSG inducing immuno-toxicity via induction of oxidative stress, the results here showed there was a positive correlation among the changes in serum IL-1 $\beta$ levels and both thymic and splenic MDA contents after MSG treatment.

Elevated glutamate concentrations could impair lymphocyte functions and induce secondary immunopathological consequences This effect of high glutamate produces the suppression of mitogeninduced proliferation and is mediated by glutamate receptors [34]. Human $\mathrm{T}$ lymphocytes express several types of glutamate receptors which control immune responses, cell activation, maturation and death [72,73]. Glutamate changes the activity of voltage-gated potassium channels and impairs $\mathrm{T}$ lymphocyte proliferation through metabotropic glutamate receptors (mGluR) [74]. Activation of lymphocytes by $\mathrm{N}$-methyl-d-aspartate (NMDAR) increases the content of intracellular calcium and reactive oxygen species $[75,76]$ and changes the secretion of both, IL-8 and IL-10 [73,77] demonstrated that glutamate affect neuroinflammation via effects on immune cells. Knockout mice lacking mGluR were markedly vulnerable to experimental autoimmune encephalomyelitis.

The study here also showed that MSG induced histological alterations in the thymus including increased numbers of lymphocytes with darkly stained nuclei and tingible body macrophages in the cortex. [13] reported that tingible body macrophages and decreased numbers of lymphocytes in the thymus might be a direct result of thymic lymphocyte toxicity. This can be attributed to oxidative stress since MSG administration significantly increased thymic MDA content along with depletion of anti-oxidants. T-lymphocytes were also reduced in the tissues of the MSG hosts. Moreover, the medullary regions were enlarged and re-populated with small lymphocytes. Cortical-medullary differentiation was difficult to be determined in dramatically affected lobules. These findings suggested shifting the balance between pro-oxidant-antioxidant systems in lymphoid organs towards pro-oxidant leading to deterioration of immune functions which may have an important role in thymocyte apoptosis induced by MSG [31].

In the current study, thymic lobules were separated by relatively thick bands and congested blood vessels. The capsules were expanded by edematous fluid with a few interspersed inflammatory cells. An earlier study indicated that tissue injury is followed by a complex set of interrelated cellular and humoral reactions. This helps to remove or neutralize injurious agents, eliminate the damaged tissue, and promote healing. Most of these reactions occur in the connective tissues and most healing ultimately depends on the deposition of collagen [78]. Empty spaces and vacuolated epithelial cells were detected in the thymus of MSG group. Most of the cells disappear from the thymus leaving highly vacuolated epithelial cells and many large to small clear vacuoles. This may be due to digestion and degeneration of apoptotic cells [10]. The depletion of interdigitating cells in the medulla may be related to a disturbance in the negative selection process of thymocytes [79].

In the current study, MSG treated group spleen showed small sized lymphatic follicles with absence of germinal centers. The differentiation between red and white pulps was indistinct. Our results are in agreement with [80] who found that administration of MSG induced degenerative and atrophic changes in rat spleen. Tetra-hydroxybutylimidazole (THI) is used as a food color additive. In rats, this compound rapidly reduced the number of $\mathrm{B}$ - and $\mathrm{T}$-lymphocytes in the peripheral blood, spleen, and lymph nodes. THI-induced immunosuppression is thought to be due to inhibited migration of mature thymocytes into the periphery. Most of the thymotoxic and immunosuppressive compounds affect secondary lymphoid organs including the spleen [79].

However, the recovery group spleen showed small sized lymphatic follicles without germinal centers. The differentiation between red and the white pulps was distinct. Our results are consistent with those of [81]. They demonstrated that there were varying degrees of cellular recovery that improved with time after cessation of MSG treatment.

As T-lymphocytes play an important role in maintaining host immune status [17], the alterations in T-lymphocyte levels in response to MSG consumption here may reflect a wider MSG-induced immunotoxicity. CD3 marker analyses of tissue sections showed that in the MSG rats, there were reduced numbers of T-lymphocytes in the cortex and moderate levels in the medulla. The recovery regimen allowed for increases in the number of T-lymphocytes in the cortex more than in the medulla. MSG also induced a decrease in $\mathrm{CD}^{+}$ T-lymphocytes in the splenic PALS. Recovery also allowed for a restoration of these cells and a re-establishing of the PALS. These were confirmed by morphometrical results which showed a significant decrease $(\mathrm{P}<0.05)$ in optical density of CD-3 expression in MSG-treated group (II) compared with control group (I). There was a significant increase $(\mathrm{P}<0.05)$ in $\mathrm{CD}-3$ expression in recovery group (III) compared with MSG-treated group (II).[82] stated that oxidative stress induces structural modifications in T-lymphocytes, leading to their becoming hypo-responsive Consequently, the oxidative stress induced by MSG could be responsible for the reduction in T-lymphocytes in both the thymus and spleen. Support for this hypothesis has been bolstered by a recent study wherein aluminum-induced oxidative stress reduced the number and density of T-lymphocytes in the spleen of pregnant rats [17].

In conclusion, a shift in the balance between pro- and anti-oxidants in the thymus and spleen following MSG administration appeared to contribute to impaired histological and immune parameters (alterations 
Citation: Hassan ZA, Arafa MH, Soliman WI, Atteia HH, Al-Saeed HF (2014) The Effects of Monosodium Glutamate on Thymic and Splenic Immune Functions and Role of Recovery (Biochemical and Histological study). J Cytol Histol 5: 283. doi:10.4172/2157-7099.1000283

in the thymus and spleen, reduction in number of T-lymphocytes in these organs, shifts in serum IL-10/IL-1 $\beta$ ratios) in treated rats which is reversible after cessation of treatment but the normal structure of the spleen would need a long time to be regained. It is recommended that further studies aimed at corroborating these findings be carried out. Based on these finding, food production agencies should take heed and potentially reduce the frequency/level of MSG addition to food products and individuals should restrict their dietary intake of foods containing this flavor enhancer.

\section{Acknowledgements}

The authors would like to thank all participants for their contribution in this study including animal house technicians and histology technicians.

\section{References}

1. Husarova V, Ostatnikova D (2013) Monosodium Glutamate Toxic Effects and Their Implications for Human Intake: A Review JMED Research 1-12.

2. Kulkarni AD, Sundaresan A, Rashid MJ, Yamamoto S, Karkow F (2014) Application of Diet-derived Taste Active Components for Clinical Nutrition: Perspectives from Ancient AyurvedicMedical Science, Space Medicine, and Modern Clinical Nutrition. Current pharmaceutical design 20: 2791-2796.

3. Bojanic V, Bojanic Z, Najman S, Savic T, Jakovljevic V, et al. (2009) Diltiazem prevention of toxic effects of monosodium glutamate on ovaries in rats. Gen Physiol Biophys 28 Spec No: 149-154

4. Jinap S, Hajeb P (2010) Glutamate. Its applications in food and contribution to health. Appetite 55: 1-10.

5. Blaylock R (2007) "Food Additives: What You Eat Can Kill You." The Blaylock Wellness Report 4.

6. US Food and Drug Administration (USFDA) (1995) FDA and Monosodium Glutamate (MSG) 1995 August 31. Bethesda, MD: U. S. Department of Health and Human Services.

7. Pavlovic V, Sarac M (2010) The role of ascorbic acid and monosodium glutamate in thymocyte apoptosis. BratisI Lek Listy 111: 357-360.

8. Williams AN, Woessner KM (2009) Monosodium glutamate 'allergy': menace or myth? Clin Exp Allergy 39: 640-646.

9. Von Diemen V, Trindade EN, Trindade MR (2006) [Experimental model to induce obesity in rats]. Acta Cir Bras 21: 425-429.

10. Shalaby NM (2009) Estradiol induced thymus alterations in adult male albino rats. Egypt J Histol 32:207-215.

11. Hakim FT, Memon SA, Cepeda R, Jones EC, Chow CK, et al. (2005) Agedependent incidence, time course, and consequences of thymic renewal in adults. J Clin Invest 115: 930-939.

12. Mebius RE, Kraal G (2005) Structure and function of the spleen. Nat Rev Immunol 5: 606-616.

13. Elmore SA (2006) Enhanced histopathology of the spleen. Toxicol Pathol 34 648-655.

14. Onkar DP, Govardhan SA (2013) Comparative histology of human and dog spleen. J Morphol Sci 30:16-20.

15. da Costa Gonçalves, Ferreira RL (2004) Dynamic regulation of GATA transcription factors in hematopoiesis. Erasmus Univ., Rotterdam.

16. She Y, Wang N, Chen C, Zhu Y, Xia S, et al. (2012) Effects of aluminum on immune functions of cultured splenic $T$ and $B$ lymphocytes in rats. Biol Trace Elem Res 147: 246-250.

17. Ayuob NN (2013) Can vitamin E and selenium alleviate the immunologic impac of aluminium on pregnant rats' spleens? Cell Immunol 284: 104-110.

18. Gao S, Wang Y, Zhang P, Dong Y, Li B (2008) Subacute oral exposure to dibromoacetic acid induced immunotoxicity and apoptosis in the spleen and thymus of the mice. Toxicol Sci 105: 331-341.

19. Nagarkatti PS, Nagarkatti M (2014) Immunotoxicology: Modulation of the immune system by xenobiotics. Defence Science Journal 37: 235-244.
20. Stack EC, Matson WR, Ferrante RJ (2008) Evidence of oxidant damage in Huntington's disease: translational strategies using antioxidants. Ann N Y Acad Sci 1147: 79-92.

21. Jin $Y$, Zhang $X$, Shu $L$, Chen $L$, Sun $L$, et al. (2010) Oxidative stress response and gene expression with atrazine exposure in adult female zebrafish (Danio rerio). Chemosphere 78: 846-852.

22. Sadowska-Woda I, Popowicz D, Karowicz-Biliß̊,ska A (2010) Bifenthrininduced oxidative stress in human erythrocytes in vitro and protective effect of selected flavonols. Toxicol In Vitro 24: 460-464.

23. Hermanussen M, García AP, Sunder M, Voigt M, Salazar V, et al. (2006) Obesity, voracity, and short stature: the impact of glutamate on the regulation of appetite. Eur J Clin Nutr 60: 25-31.

24. Hlinák Z, Gandalovicová D, Krejcí I (2005) Behavioral deficits in adult rats treated neonatally with glutamate. Neurotoxicol Teratol 27: 465-473.

25. Narayanan SN, Kumar RS, Paval J, Nayak S (2010) Effect of ascorbic acid on the monosodium glutamate-induced neurobehavioral changes in periadolescent rats. Bratisl Lek Listy 111: 247-252.

26. Nwaopara AO, Anyanwu LC, Oyinbo CA, Anaikot IC (2004) Histological changes in pancreas of Wistar rats fed diets containing Yaji (local meat sauce) J Exp Clin Anat 3: 44- 47

27. Nwaopara AO, Odike MA, Inegbenebor U, Adoye MI (2007) The combined effects of excessive consumption of ginger, clove, red pepper, and black pepper on histology of the liver Pakistan J Nutr 6: 524-527.

28. Nwaopara AO, Odike MA, Inegbenebor U, Nwaopara SO, Ewere GI (2008) A comparative study on effects of excessive consumption of ginger, clove, red pepper, and black pepper on histology of the kidney. Pakistan J Nutr 7: 287291.

29. Singh P, Mann KA, Mangat HK, Kaur G (2003) Prolonged glutamate excitotoxicity: effects on mitochondrial antioxidants and antioxidant enzymes. Mol Cell Biochem 243: 139-145.

30. Farombi EO, Onyema OO (2006) Monosodium glutamate-induced oxidative damage and genotoxicity in the rat: modulatory role of vitamin $C$, vitamin $E$ and quercetin. Hum Exp Toxicol 25: 251-259.

31. Pavlovic V, Pavlovic D, Kocic G, Sokolovic D, Jevtovic-Stoimenov T, et al. (2007) Effect of monosodium glutamate on oxidative stress and apoptosis in rat thymus. Mol Cell Biochem 303: 161-166.

32. Martin LJ, Sieber FE, Traystman RJ (2000) Apoptosis and necrosis occur in separate neuronal populations in hippocampus and cerebellum after ischemia and are associated with differential alterations in metabotropic glutamate receptor signaling pathways. J Cereb Blood Flow Metab 20: 153-167.

33. Pavlovic V, Cekic S, Kocic G, Sokolovic D, Zivkovic V (2007) Effect of monosodium glutamate on apoptosis and $\mathrm{Bcl}-2 / \mathrm{Bax}$ protein level in rat thymocyte culture. Physiol Res 56: 619-626.

34. Pacheco R, Gallart T, Lluis C, Franco R (2007) Role of glutamate on T-cell mediated immunity. J Neuroimmunol 185: 9-19.

35. Seo HJ, Ham HD, Jin HY, Lee WH, Hwang HS, et al. (2010) Chronic administration of monosodium glutamate under chronic variable stress impaired hypothalamic pituitary adrenal axis function in rats. Korean J Physio Pharmacol 14: 213-221.

36. lamsaard S, Sukhorum W, Samrid R, Yimdee J, Kanla P, et al. (2014) The sensitivity of male rat reproductive organs to monosodium glutamate. Acta Med Acad 43: 3-9.

37. Kolawole OT (2013) Assessment of the effects of monosodium glutamate on some biochemical and hematological parameters in adult wistar rats. American Journal of BioScience 1: 11-15.

38. Ohguro H, Katsushima H, Maruyama I, Maeda T, Yanagihashi S, et al. (2002) A high dietary intake of sodium glutamate as flavoring (ajinomoto) causes gross changes in retinal morphology and function. Exp Eye Res 75: 307-315.

39. Kingsley OA, Jacks PTW, Amaza DS, Peters TM, Otong ES (2013) The Effect of Monosodium Glutamate (MSG) on the Gross Weight of the Heart of Albino Rats. Sch J App Med Sci 1: 44-47.

40. Ahmed AE, Hussein GI, Loh JP, Abdel-Rahman SZ (1991) Studies on the mechanism of haloacetonitrile-induced gastrointestinal toxicity: interaction of dibromoacetonitrile with glutathione and glutathione-S-transferase in rats. Biochem Toxicol 6: 115-121.[40] 
Citation: Hassan ZA, Arafa MH, Soliman WI, Atteia HH, Al-Saeed HF (2014) The Effects of Monosodium Glutamate on Thymic and Splenic Immune Functions and Role of Recovery (Biochemical and Histological study). J Cytol Histol 5: 283. doi:10.4172/2157-7099.1000283

41. Gendy A, El-Abhar H, Mohsen AR (2014) Cilostazol Hepatoprotective Effect Against Ischemia/Reperfusion: Involvement of GSK-3ß, Cyclin D1 and Wnt/ß catenin Pathway. Journal of Pharmacology Research 4: 75-81.

42. Aebi H (1984) Catalase in vitro. Methods Enzymol 105: 121-126.

43. Shahid M, Dumat C, Pourrut B, Silvestre J, Laplanche C, et al. (2014) Influence of EDTA and citric acid on lead-induced oxidative stress to Vicia faba roots. Journal of Soils and Sediments 14: 835-843.

44. Nishikimi M, Appaji N, Yagi K (1972) The occurrence of superoxide anion in the reaction of reduced phenazine methosulfate and molecular oxygen. Biochem Biophys Res Commun 46: 849-854.

45. Attia AM., Ibrahim FA, EL-Latif NAA., Aziz SW (2014) Antioxidant effects of curcumin against cadmium chloride-induced oxidative stress in the blood of rats. Journal of Pharmacognosy and Phytotherapy 6: 33-40.

46. Bancroft J, Gamble A (2002) Theory and Practice of Histological Techniques 5th Edition. London: Churchil, Livingstone.

47. Kiernan JA (2007) Immunohistochemical staining of inflammation and an artifact. Biotech Histochem 82: 273-274.

48. Beyreuther K, Biesalski HK, Fernstrom JD, Grimm P, Hammes WP, et al. (2007) Consensus meeting: monosodium glutamate - an update. Eur J Clin Nutr 61 304-313.

49. Tome ME, Baker AF, Powis G, Payne CM, Briehl MM (2001) Catalaseoverexpressing thymocytes are resistant to glucocorticoid-induced apoptosis and exhibit increased net tumor growth. Cancer Res 61: 2766-2773.

50. Szelényi J (2001) Cytokines and the central nervous system. Brain Res Bull 54: 329-338.

51. Abou-Raya A, Abou-Raya S (2006) Inflammation: a pivotal link between autoimmune diseases and atherosclerosis. Autoimmun Rev 5: 331-337.

52. Kanterman J, Sade-Feldman M, Baniyash M (2012) New insights into chronic inflammation-induced immunosuppression. Semin Cancer Biol 22: 307-318.

53. Kim MS, Yi JM, Kim SH, Hong SH, Kim HM (2004) Madimadi, Korean folk medicine, blocks TNF-alpha, IL-1beta, and IL-8 production by activated human immune cells. Cytokine 25: 179-186

54. Liu C, Li M, Cao Y1, Qu JP1, Zhang ZW1, et al. (2014) Effects of avermectin on immune function and oxidative stress in the pigeon spleen. Chem Biol Interact 210: 43-50.

55. Alarcon-Aguilar FJ, Almanza-Perez J, Blancas G, Angeles S, Garcia-Macedo $R$, et al. (2008) Glycine regulates the production of pro-inflammatory cytokines in lean and monosodium glutamate-obese mice. Eur J Pharmacol 599: 152158.

56. Furuya DT, Poletto AC, Favaro RR, Martins JO, Zorn TM, et al. (2010) Anti-inflammatory effect of atorvastatin ameliorates insulin resistance in monosodium glutamate-treated obese mice. Metabolism 59: 395-399.

57. Roman-Ramos R, Almanza-Perez JC, Garcia-Macedo R, Blancas-Flores G Fortis-Barrera A, et al. (2011) Monosodium glutamate neonatal intoxication associated with obesity in adult stage is characterized by chronic inflammation and increased mRNA expression of peroxisome proliferator-activated receptors in mice. Basic Clin Pharmacol Toxicol 108: 406-413.

58. Das UN (2001) Is obesity an inflammatory condition? Nutrition 17: 953-966.

59. Bastard JP, Maachi M, Lagathu C, Kim MJ, Caron M, et al. (2006) Recen advances in the relationship between obesity, inflammation, and insulin resistance. Eur Cytokine Netw 17: 4-12.

60. Kern PA, Ranganathan S, Li C, Wood L, Ranganathan G (2001) Adipose tissue tumor necrosis factor and interleukin- 6 expression in human obesity and insulin resistance. Am J Physiol Endocrinol Metab 280: E745-751.

61. Pestka S, Krause CD, Sarkar D, Walter MR, Shi Y, et al. (2004) Interleukin-10 and related cytokines and receptors. Annu Rev Immunol 22: 929-979.

62. Gotoh K, Inoue M, Masaki T, Chiba S, Shimasaki T, et al. (2012) A novel antiinflammatory role for spleen-derived IL-10 in obesity-induced hypothalamic inflammation. J Neurochem 120: 752-764.

63. Zhou Z, Peng X, Insolera R, Fink DJ, Mata M (2009) IL-10 promotes neuronal survival following spinal cord injury. Exp Neurol 220: 183-190.

64. Poitevin S, Ben Hadj Kalifa Kechiche S, Macé C, Nguyen P (2009) IL-10 inhibits apoptosis and microvesiculation of human monocytes. J Thromb Haemost 7: 1241-1243.
65. Martin KR, Kari FW, Barrett JC, French JE (2000) N-acetyl-L-cysteine simultaneously increases mitogenesis and suppresses apoptosis in mitogenstimulated B-lymphocytes from p53 haploinsufficient Tg.AC (v-Ha-ras) mice. In Vitr Mol Toxicol 13: 237-248.

66. Aluigi MG, Guida C, Falugi C (2010) Apoptosis as a specific biomarker of diazinon toxicity in NTera2-D1 cells. Chem Biol Interact 187: 299-303.

67. Stephen TL, Tikhonova A, Riberdy JM, Laufer TM (2009) The activation threshold of CD4+ T cells is defined by TCR/peptide-MHC class II interactions in the thymic medulla. J Immunol 183: 5554-5562.

68. Rehman H, Ali M, Atif F, Kaur M, Bhatia K, et al. (2006) The modulatory effect of deltamethrin on antioxidants in mice. Clin Chim Acta 369: 61-65.

69. El-Demerdash FM (2007) Lambda-cyhalothrin-induced changes in oxidative stress biomarkers in rabbit erythrocytes and alleviation effect of some antioxidants. Toxicol In Vitro 21: 392-397.

70. Jin Y, Zheng S, Pu Y, Shu L, Sun L, et al. (2011) Cypermethrin has the potentia to induce hepatic oxidative stress, DNA damage and apoptosis in adult zebrafish (Danio rerio). Chemosphere 82: 398-404.

71. Jin Y, Pan X, Fu Z (2014) Exposure to bifenthrin causes immunotoxicity and oxidative stress in male mice. Environ Toxicol 29: 991-999.

72. Chiocchetti A, Miglio G, Mesturini R, Varsaldi F, Mocellin M, et al. (2006) Group I mGlu receptor stimulation inhibits activation-induced cell death of human $T$ lymphocytes. Br J Pharmacol 148: 760-768.

73. Kvaratskhelia E, Maisuradze E, Dabrundashvili NG, Natsvlishvili N, Zhuravliova E, et al. (2009) N-methyl-D-aspartate and sigma-ligands change the production of interleukins 8 and 10 in lymphocytes through modulation of the NMDA glutamate receptor. Neuroimmunomodulation 16: 201-207.

74. Poulopoulou C, Markakis I, Davaki P, Nikolaou C, Poulopoulos A, et al. (2005) Modulation of voltage-gated potassium channels in human $T$ lymphocytes by extracellular glutamate. Mol Pharmacol 67: 856-867.

75. Miglio G, Varsaldi F, Lombardi G (2005) Human T lymphocytes express $\mathrm{N}$-methyl-D-aspartate receptors functionally active in controlling $\mathrm{T}$ cell activation. Biochem Biophys Res Commun 338: 1875-1883.

76. Boldyrev AA, Kazey VI, Leinsoo TA, Mashkina AP, Tyulina OV, et al. (2004) Rodent lymphocytes express functionally active glutamate receptors. Biochem Biophys Res Commun 324: 133-139.

77. Fallarino F, Volpi C, Fazio F, Notartomaso S, Vacca C, et al. (2010) Metabotropic glutamate receptor- 4 modulates adaptive immunity and restrains neuroinflammation. Nature Medicine 16: 897-902.

78. Cotran RS, Kumar V, Robbins SL (1994) Cellular injury and cellular death. In: Robbin's Pathologic Basis of Diseases. 5th Edition. Philadelphia: WB Saunders Comp.

79. Kuper CF, Harleman JH, Richter-Reichelm HB, Vos JG (2000) Histopathologic approaches to detect changes indicative of immunotoxicity. Toxicol Pathol 28 : 454-466.

80. Ciric M, Cekic S, Pavlovic V, Jovic Z, Tasic G (2005) Histopathological changes In spleen of rats treated with monosodium glutamate. Acta Fac. Med. Naiss 22:191-194.

81. Ebaid HM, Tag HM (2012) Monosodium glutamate toxic effect on spleen structure and potential of recovery in adult albino rats. Egypt Acad J Biol Sci. 4: $1-8$.

82. Cemerski S, van Meerwijk JP, Romagnoli P (2003) Oxidative-stress-induced $T$ lymphocyte hyporesponsiveness is caused by structural modification rather than proteasomal degradation of crucial TCR signaling molecules. Eur $\mathrm{J}$ Immunol 33: 2178-2185 